\title{
Stabilnost samospoštovanja $v$ odnosu do narcisizma in psihološkega blagostanja
}

\author{
Saša Zorjan ${ }^{1 *}$ in Katja Košir ${ }^{2}$ \\ ${ }^{1}$ Maribor \\ ${ }^{2}$ Oddelek za temeljne pedagoške predmete, Pedagoška fakulteta, Univerza v Mariboru
}

\begin{abstract}
Povzetek: Koncept stabilnosti samospoštovanja ima pomembno vlogo pri razumevanju medosebnega in psihološkega funkcioniranja posameznikov. Namen pričujoče raziskave je bil preveriti odnos med stabilnostjo samospoštovanja, narcisizmom in psihološkim blagostanjem. V raziskavi je sodelovalo 178 udeležencev ( 77 \% žensk). Povprečna starost udeležencev je bila 20 let, v razponu od 18 do 26 let. Udeleženci so reševali vprašalnik narcisizma NPI, vprašalnik psihološkega blagostanja PWBS, lestvico nestabilnosti samospoštovanja ISES in lestvico samospoštovanja RSES. Lestvica samospoštovanja RSES je bila uporabljena za oceno tako stopnje kot stabilnosti samospoštovanja; slednjo smo operacionalizirali kot razpršenost stopnje samospoštovanja $\mathrm{v}$ času. Za namene pridobitve podatka o stabilnosti samospoštovanja so udeleženci lestvico samospoštovanja reševali 14 dni zapored, medtem ko so ostale mere izpolnili prvi dan sodelovanja. Glavni učinek stopnje samospoštovanja se je pokazal tako v odnosu do narcisizma kot psihološkega blagostanja, v obeh primerih so se z višanjem stopnje samospoštovanja višale tudi vrednosti narcisizma ter psihološkega blagostanja. Stabilnost samospoštovanja (razpršenost stopnje samospoštovanja $\mathrm{v}$ času) je, ob upoštevanju stopnje samospoštovanja, dodatno pojasnila statistično pomemben delež variance narcisizma in psihološkega blagostanja. Višje vrednosti stabilnosti samospoštovanja so se povezovale z nižjimi vrednostmi narcisizma ter višjimi vrednostmi psihološkega blagostanja. Ob primerjanju dveh različnih mer stabilnosti samospoštovanja smo ugotovili prisotnost precenjevanja stabilnosti samospoštovanja pri posameznikih z bolj izraženim narcisizmom. Dobljeni rezultati so bili v skladu s postavljenimi hipotezami. V diskusiji je izpostavljena pomembnost upoštevanja tako stopnje kot stabilnosti samospoštovanja. Izpostavljene so tudi pomanjkljivosti pričujoče raziskave ter možnosti za nadaljnje raziskovanje.
\end{abstract}

Ključne besede: samospoštovanje, narcisizem, psihološko blagostanje

\section{Self-esteem stability in relation to narcissism and psychological well-being}

\author{
Saša Zorjan ${ }^{1}$ and Katja Košir ${ }^{2}$ \\ ${ }^{1}$ Maribor, Slovenia \\ ${ }^{2}$ Department of Basic Pedagogical Studies, Faculty of Education, University of Maribor, Slovenia
}

\begin{abstract}
The concept of self-esteem stability has an important role in the understanding of interpersonal and psychological functioning of individuals. The purpose of this study was to examine the relationship between self-esteem stability, narcissism and psychological well-being. A total of 178 participants $(77 \%$ female) participated in this study. The average age of the participants was 20, with the ages ranging from 18 to 26 years. The participants completed the following scales and questionnaires: Narcissistic Personality Inventory (NPI), Psychological Well-being Scales (PWBS), Instability of Selfesteem scale (ISES) and Rosenberg Self-esteem scale (RSES). The Rosenberg Self-esteem scale was used to measure both self-esteem level and self-esteem stability, which was defined as dispersion of self-esteem level in time. For the purpose of obtaining data on self-esteem stability, the participants were required complete the Rosenberg self-esteem scale for a sequence of 14 days, other measures were completed during the first day of participation in the study. The main effects for self-esteem level emerged for narcissism and psychological well-being, in both cases higher levels of self-esteem was associated to higher levels of narcissism and psychological well-being. Self-esteem stability additionally explained a significant proportion of variability in narcissism and psychological well-being. Self-esteem stability was negatively associated with higher levels of narcissism and positively associated with higher levels of psychological well-being, above and beyond the effect of self-esteem level. When comparing two different measures of self-esteem stability, the results revealed that people with higher level of narcissism tend to overestimate their self-esteem stability. The results were consistent with our hypotheses. The importance of considering both level and stability of self-esteem, limitations of the present study and possibilities for further research are also discussed.
\end{abstract}

Keywords: self-esteem, narcissism, psychological well-being

${ }^{\bar{*}}$ Naslov/Address: Saša Zorjan, Smetanova ulica 80, 2000 Maribor, e-mail: sasa.zorjan@gmail.com

Članek je licenciran pod pogoji Creative Commons Attribution 4.0 licence. / The article is licensed under a Creative Commons Attribution 4.0 International License. 


\section{Stopnja in stabilnost samospoštovanja}

Samospoštovanje je konstrukt, ki je že dolga leta predmet psiholoških raziskav. Najpogosteje se za merjenje samospoštovanja uporablja splošni faktor, ki predstavlja samospoštovanje kot osebnostno lastnost, neodvisno od konteksta in vsebine. Tako na primer Rosenberg (1989; v Kobal Grum in Avsec, 2007) definira samospoštovanje kot pozitivno oziroma negativno stališče do sebe.

Čeprav so raziskave, ki preučujejo samospoštovanje, pogoste, ostaja vloga le-tega v psihološkem funkcioniranju nejasna. Raziskovalci so namreč ugotovili, da se samopodoba in samospoštovanje z nekaterimi fenomeni, kot sta na primer učna uspešnost in delinkventno vedenje, povezujeta tako negativno kot pozitivno (Skaalvik in Hagtvet, 1990). Ob pregledu literature s področja stopnje samospoštovanja (angl. self-esteem level) lahko ugotovimo, da ta ni vedno dober napovednik izidov, kot so učna uspešnost, poklicni uspeh, zloraba škodljivih substanc in kriminaliteta (Baumeister, Campbell, Kreuger in Vohs, 2003). Še posebej veliko neskladnih ugotovitev se pojavlja v zvezi s posamezniki z zelo visoko stopnjo samospoštovanja. Raziskave so namreč ugotovile, da so posamezniki z visokim samospoštovanjem zelo defenzivni, ko se soočijo z dejavniki, ki ogrožajo občutek lastne vrednosti (Baumeister, Heatherton in Tice, 1993). Te ugotovitve pa se zelo razlikujejo od pojmovanj znotraj kliničnega in humanističnega pogleda na samospoštovanje (Rogers, 1959; v Kernis, 2005). Predpostavlja se namreč, da negativne povratne informacije oziroma slab nastop na samovrednotenje posameznika, ki je sam s sabo resnično zadovoljen ter ima visoko samospoštovanje, ne morejo vplivati. Pri posameznikih z visokim samospoštovanjem bi torej pričakovali manj obrambnega odzivanja na dogodke, ki ogrožajo njihov občutek lastne vrednosti. Stopnja samospoštovanja sama po sebi torej prikazuje nepopolno sliko vloge samospoštovanja v psihološkem in medosebnem funkcioniranju.

$\mathrm{V}$ novejše raziskave $\mathrm{s}$ področja samospoštovanja avtorji poleg stopnje samospoštovanja vključujejo dodatni vidik samospoštovanja: stabilno proti nestabilnemu (angl. stable vs. unstable) samospoštovanju (Kernis in Lakey, 2010). Tako se posamezniki, katerih stopnja samospoštovanja je enaka (nizka/visoka), lahko bistveno razlikujejo po stabilnosti samospoštovanja. Posledično se bodo bistveno razlikovali tudi njihovi odzivi na dogajanje okoli njih in njihovo zaznavanje sveta. To lahko nazorno prikažemo pri posameznikih z visokim samospoštovanjem, ki se razlikujejo glede na stabilnost letega. Posamezniki s stabilnim visokim samospoštovanjem so zadovoljni s sabo, imajo občutke lastne vrednosti, ki so dobro zasidrani in relativno stabilni. Sprejemajo svoje slabosti in nimajo potrebe po superiornosti nad drugimi. Samospoštovanje jim je »dano« in si jim ga ni potrebno prislužiti ali potrjevati dan za dnem. Nasprotno pa nestabilno visoko samospoštovanje vključuje pozitivne, vendar plitve občutke lastne vrednosti, ki pogosto nihajo iz dneva v dan. Pri posameznikih z nestabilnim visokim samospoštovanjem so občutki njihove lastne vrednosti pogosto odvisni od zunanjih kriterijev odličnosti, kot so na primer nadpovprečni dosežki na učnem ali športnem področju, privlačnost ali priljubljenost. Njihovi občutki lastne vrednosti se lahko ob pomanjkanju konstantnih zunanjih potrditev hitro znižajo (Kernis in Lakey, 2010).

Čeprav se koncept stabilnosti samospoštovanja pogosteje pojavlja v novejših raziskavah, ga je opisal že James (1950; v Kernis, Cornell, Sun, Berry in Harlow, 1993). Za tem ga je natančneje definiral še Rosenberg (1986; v Kernis in Lakey, 2010). Uporabil je izraz barometrično (angl. barometric) samospoštovanje, $\mathrm{s}$ čimer je imel $\mathrm{v}$ mislih kratkoročna nihanja $\mathrm{v}$ stopnji samospoštovanja. Stabilnost samospoštovanja se torej nanaša na velikost kratkoročnih nihanj, ki jih ljudje doživljamo $\mathrm{v}$ naših kontekstualno odvisnih vrednostnih sodbah o samih sebi, z drugimi besedami; gre za razpršenost stopnje samospoštovanja $\mathrm{v}$ času. Skladno $s$ to definicijo se stabilnost samospoštovanja opredeli kot standardni odklon posameznikovih vsakodnevnih rezultatov na lestvici samospoštovanja. Večji standardni odklon nakazuje na bolj nestabilno samospoštovanje, medtem ko manjši standardni odklon nakazuje na večjo stabilnost samospoštovanja.

Nestabilnost samospoštovanja kaže na krhke in ranljive občutke o samem sebi, ki so pod močnim vplivom spremenljivih zunanjih informacij ter percepcij le-teh (Kernis, 2005). Pomen koncepta stabilnosti samospoštovanja za psihološko funkcioniranje je v stroki dobro empirično dokumentiran. Nestabilno samospoštovanje se povezuje $\mathrm{z}$ depresivnim razpoloženjem pri posameznikih, ki doživijo neuspeh (Roberts in Monroe, 1992), nejasno samopodobo (Kernis, Paradise, Whitaker, Wheatman in Goldman, 2000), večjo reaktivnostjo občutkov o samem sebi glede na vsakodnevne pozitivne in negativne dogodke (Greenier idr., 1999) in nižjo intrinzično motivacijo (Waschull in Kernis, 1996). Te in podobne ugotovitve nakazujejo na to, da imajo posamezniki z nestabilnim samospoštovanjem krhke občutke lastne vrednosti, ki so močno odvisni od dogodkov, ki so za posameznika pomembni. Pozitivna ocena lastne vrednosti je za te posameznike nujno odvisna od povratnih informacij iz zunanjega sveta in zunanje postavljenih kriterijev vrednosti posameznika. Pozitivna samopodoba in visoko samospoštovanje za njih nista mogoča brez posameznikov okoli njih, ki jim njihovo vrednost potrjujejo znova in znova. Iz teh razlogov so posamezniki $\mathrm{z}$ nestabilnim samospoštovanjem zelo defenzivni in bolj nagnjeni $\mathrm{k}$ pretirani samopromociji (Kernis in Lakey, 2010).

Poleg psiholoških vidikov ima lahko stabilnost samospoštovanja tudi pomembno vlogo pri napovedni vrednosti mer samospoštovanja. Posamezniki s stabilnim samospoštovanjem namreč manj variirajo $\mathrm{v}$ stopnji samospoštovanja na vsakodnevni ravni kot posamezniki z nestabilnim samospoštovanjem. To pomeni, da za posameznike s stabilnim samospoštovanjem obstaja večja verjetnost, da bodo njihove trenutne globalne samoocene bolj kongruentne $\mathrm{z}$ njihovo splošno stopnjo samospoštovanja. Vsak napovedni odnos, ki 
ga najdemo med stopnjo samospoštovanja in kakšnim drugim konstruktom (na primer narcisizem, psihološko blagostanje), je torej močnejši zaradi teh posameznikov. Pri posameznikih z nestabilnim samospoštovanjem pa se lahko njihove trenutne globalne samoocene zelo razlikujejo od njihove povprečne stopnje samospoštovanja. Posledično je napovedni odnos med stopnjo samospoštovanja in drugimi spremenljivkami šibkejši ravno zaradi takih posameznikov (Kernis, Grannemann in Mathis, 1991).

\section{Stabilnost samospoštovanja v odnosu do narcisizma}

Ob pregledu empirično ugotovljenih značilnosti posameznikov z nestabilnim samospoštovanjem lahko potegnemo vzporednice $\mathrm{z}$ opredelitvami posameznikov $\mathrm{z}$ visoko izraženo osebnostno potezo narcisizma. Enako kot posamezniki $\mathrm{z}$ nestabilnim visokim samospoštovanjem se tudi posamezniki z visoko izraženim narcisizmom bolj reaktivno odzivajo na dogodke, ki so pomembni za oceno samega sebe (Bosson idr., 2008).

Visoko izražena osebnostna poteza narcisizma se povezuje $\mathrm{z}$ grandioznimi prepričanji glede lastne inteligentnosti, moči, fizične privlačnosti ter lastne unikatnosti. Raziskave tako konsistentno potrjujejo povezanost narcisizma in visoke stopnje samospoštovanja (Campbell in Buffardi, 1998). Raziskave vedno znova potrjujejo tudi precenjevanje pozitivnih lastnosti $\mathrm{s}$ strani posameznikov z bolj izraženim narcisizmom ter netočnost njihovih samozaznav (Buffardi in Campbell, 2008). Stabilnost samospoštovanja je konstrukt, ki ima pozitivno konotacijo, zato je utemeljeno pričakovati, da bo pri posameznikih $\mathrm{z}$ visoko izraženim narcisizmom tudi na tem področju prišlo do precenjevanja.

Osrednja predpostavka v večini teoretičnih modelov narcisizma $\mathrm{v}$ socialni psihologiji je uporaba socialnih odnosov za regulacijo samospoštovanja ter ohranjanje pozitivne samopodobe (glej npr. Campbell, 1999; Campbell, Brunell in Finkel, 2006; Morf in Rhodewalt, 1993). Posamezniki z visoko izraženo potezo narcisizma so torej bolj odvisni od zunanjih socialnih odnosov ter povratnih informacij kot tisti $\mathrm{z}$ nizko izraženo potezo narcisizma. To je $\mathrm{v}$ neki meri pogojeno $\mathrm{z}$ visoko emocionalno reaktivnostjo, ki je pri posameznikih $\mathrm{z}$ visoko izraženim narcisizmom povezana s povratnimi informacijami, ki se nanašajo na posameznika(Rhodewalt, Madrian in Cheney, 1998). Bolj kot od samih zunanjih dogodkov so posamezniki z bolj izraženim narcisizmom odvisni od povratnih informacij o njih samih. To napeljuje na predpostavko, da bodo vrednostne sodbe posameznikov z visoko izraženim narcisizmom o njih samih v splošnem pozitivne, vendar hkrati zelo nestabilne. Sklepamo lahko torej, da se bo stabilnost samospoštovanja, ob upoštevanju učinkov stopnje samospoštovanja, z narcisizmom povezovala negativno. Rezultati dosedanjih raziskav so precej nekonsistentni, saj so določene raziskave negativen odnos med narcisizmom in stabilnostjo samospoštovanja potrdile (Rhodewalt idr., 1998), medtem ko druge niso našle povezave (Bosson idr., 2008; Webster, Kirkpatrick, Nezlek, Smith in Paddock, 2007).

\section{Stabilnost samospoštovanja v odnosu do psihološkega blagostanja}

Stabilnost samospoštovanja se konceptualno povezuje tudi s psihičnim blagostanjem, ki ga definiramo kot posameznikovo kognitivno in afektivno oceno lastnega življenja (Ryff, 1989). Natančneje lahko koncept opredelimo kot psihološko blagostanje, ki ga lahko še bolj natančno definiramo z vključitvijo več komponent psihološkega blagostanja in tako zajema (1) sprejemanje sebe; (2) pozitivne medosebne odnose; (3) življenjski smisel; (4) osebno rast; (5) obvladovanje okolja in (6) avtonomnost. Opisan multifacetni pristop integrira bolj specifične konceptualizacije blagostanja, ki so se oblikovale znotraj področij duševnega zdravja, klinične psihologije, socialne psihologije ter psihologije osebnosti (Ryff, 1989).

Psihološko blagostanje je pomemben vidik posameznikovega psihološkega funkcioniranja in se pozitivno povezuje s stopnjo samospoštovanja (Baumeister idr., 2003; Ryff, 1989), vse več pozornosti pa se namenja tudi vlogi stabilnosti samospoštovanja $\mathrm{V}$ povezavi $\mathrm{s}$ psihološkim blagostanjem. V preteklih raziskavah je bilo ugotovljeno, da ima stabilnost samospoštovanja pomembno napovedno vrednost v odnosu do psihološkega blagostanja, tudi ob upoštevanju stopnje samospoštovanja (Paradise in Kernis, 2002). Te ugotovitve so skladne s teoretičnimi predpostavkami ter jih lahko utemeljimo $s$ tem, da posamezniki z nestabilnim samospoštovanjem niso popolnoma prepričani o lastni vrednosti ter, da so njihove ocene samih sebe pogosto pogojene $\mathrm{s} » k$ kriteriji odličnosti«, kot so uspeh na področju šolanja, športa ali privlačnost. Če v kakšni aktivnosti ne uspejo, se takoj vrednotijo veliko slabše kot sicer (Kernis in Lakey, 2010).

Dodatne raziskave so pokazale, da se učinki stabilnosti samospoštovanja na funkcioniranje posameznikov razlikujejo, ko primerjamo posameznike $\mathrm{z}$ visokim in nizkim samospoštovanjem. Odnos med stabilnostjo samospoštovanja in psihološkim blagostanjem se je v preteklih raziskavah preučeval pretežno pri posameznikih z visokim samospoštovanjem. Pri njih pričakujemo, da bo s stabilnostjo samospoštovanja naraščalo tudi psihološko blagostanje (Paradise in Kernis, 2002). Povedano na drugačen način, najvišje vrednosti psihološkega blagostanja pričakujemo pri posameznikih s kombinacijo tako visoke stopnje samospoštovanja kot tudi visoke stabilnosti samospoštovanja. Razlike med posamezniki s stabilnim in nestabilnim nizkim samospoštovanjem pa so veliko manj jasne, saj je bilo na tem področju izvedenih bistveno manj raziskav. Na podlagi ugotovitev, ki so preučevale vlogo stabilnosti samospoštovanja na drugih področjih psihološkega funkcioniranja, lahko vseeno predvidimo, da bo nestabilnost samospoštovanja povezana z nižjimi vrednostmi psihološkega blagostanja, tudi pri posameznikih z nizko stopnjo samospoštovanja. Večina raziskav namreč ugotavlja, da je nestabilnost samospoštovanja povezana $\mathrm{z}$ manj optimalnim psihološkim funkcioniranjem (Greenier idr., 1999, 
Kernis idr., 2000; Roberts in Monroe, 1992; Waschull in Kernis, 1996). Predvidevamo, da se bo podoben vzorec pokazal tudi $\mathrm{v}$ odnosu do psihološkega blagostanja; posamezniki s kombinacijo nizke stopnje in nizke stabilnosti samospoštovanja bodo dosegali nižje vrednosti psihološkega blagostanja.

\section{Namen}

Z raziskavo smo želeli natančneje preveriti odnos med stabilnostjo samospoštovanja, narcisizmom ter psihološkim blagostanjem. Zanimalo nas je predvsem, ali ima stabilnost samospoštovanja, ob upoštevanju stopnje samospoštovanja ter nekaterih demografskih spremenljivk, dodatno napovedno vrednost.

Predpostavljali smo, da bosta tako stopnja kot stabilnost samospoštovanja pomembna napovednika rezultatov na lestvici narcisizma. Zanimala nas je tudi točnost ocene stabilnosti samospoštovanja, kjer smo predvidevali, da bodo posamezniki z bolj izraženim narcisizmom v večji meri precenjevali stabilnost svojega samospoštovanja $\mathrm{v}$ primerjavi $\mathrm{s}$ posamezniki $\mathrm{z}$ manj izraženim narcisizmom.

Predpostavili smo tudi, da bosta tako stopnja kot stabilnost samospoštovanja pomembna napovednika psihološkega blagostanja, ter da bo kombinacija visoke stopnje in stabilnosti samospoštovanja rezultirala $\mathrm{V}$ najvišjih vrednostih psihološkega blagostanja.

\section{Metoda}

\section{Udeleženci}

$\mathrm{V}$ raziskavo smo vključili 199 študentov Univerze v Mariboru (91,6 \%) in Univerze v Ljubljani (8,4 \%). Udeležence, ki vprašalnikov niso izpolnjevali vseh 14 dni, smo iz nadaljnjih analiz izločili. V nadaljnje analize smo vključili 178 udeležencev $(89,4$ \%), od tega 77 \% ženskega spola. Povprečna starost udeležencev je 20 let $(S D=1,58)$, v razponu od 18 do 26 let. Udeleženci so študenti različnih smeri, med njimi je največ študentov sociologije (40,5\%), sledijo študenti psihologije (34,3\%), predšolske vzgoje $(9,1 \%)$, računalništva in informatike $(2,3 \%)$ in nekaterih drugih smeri (manj kot $2 \%$ ).

Študenti Filozofske fakultete Univerze v Mariboru $(74,7 \%)$ so za sodelovanje $\mathrm{v}$ raziskavi dobili dodatnih 5 odstotkov pri zaključni oceni pri vajah iz psihologije. Drugi udeleženci za sodelovanje niso bili nagrajeni.

\section{Pripomočki}

Lestvica samospoštovanja RSES. Avtor lestvice je Morris Rosenberg (1965; v Zeigler-Hill, 2006). Uporabili smo slovensko priredbo lestvice (Lamovec, n.d.; v Avsec, 2007). Vsebuje 10 postavk (na primer: Imam številne dobre lastnosti). Udeleženci pri vsaki postavki na štiristopenjski lestvici (od 0 do 3 ) ocenijo, v kolikšni meri trditev za njih drži.
Koeficient notranje skladnosti na naših podatkih znaša 0,89. Rosenberg (1965; v Zeigler-Hill, 2006) navaja nekoliko nižji koeficient $(\alpha=0,82)$. A. Avsec (2007) poroča o podobnem koeficientu notranje skladnosti na slovenskem vzorcu $(\alpha=0,81)$. S komponentno analizo smo potrdili enodimenzionalno strukturo te lestvice tudi na našem vzorcu; izločena komponenta pojasni 44,73 \% variance. Lestvica samospoštovanja je v osnovi namenjena oceni stopnje samospoštovanja, vendar jo lahko ob vzdolžnem merjenju uporabimo tudi kot mero stabilnosti samospoštovanja (Kernis, 2005). V nadaljevanju je podrobneje opisan proces ocene stopnje in stabilnosti samospoštovanja s pomočjo lestvice samospoštovanja RSES.

Stopnjo samospoštovanja smo s pomočjo te lestvice pridobili na dva načina. Prvo oceno udeleženčeve stopnje samospoštovanja smo dobili $\mathrm{z}$ rezultatom na lestvici RSES prvi dan sodelovanja $\mathrm{v}$ raziskavi. Drugo oceno stopnje samospoštovanja pa smo pridobili na podlagi izračuna povprečja vsakodnevnih doseženih rezultatov na lestvici RSES. Za namene vsakodnevne rabe lestvice smo prilagodili navodilo in udeležencem naročili, naj odgovarjajo v skladu s trenutnim počutjem. V raziskavah sta bila uporabljena oba pristopa (Kernis idr., 1991). Obe oceni stopnje samospoštovanja na našem vzorcu zelo visoko pozitivno korelirata $(\rho=0,92, p<0,01)^{1}$, zato smo v analize vključili le eno izmed ocen (povprečje vsakodnevnih rezultatov). Visoko število točk pomeni pozitivnost posameznikove globalne ocene o sebi (Avsec, 2007).

Stabilnost samospoštovanja ${ }^{2}$ smo ocenili s pomočjo vsakodnevnih rezultatov na lestvici samospoštovanja RSES. Za vsakega od udeležencev smo izračunali standardno deviacijo vsakodnevnih rezultatov na lestvici samospoštovanja. Višja standardna deviacija predstavlja bolj nestabilno samospoštovanje.

Lestvica nestabilnosti samospoštovanja ISES. ${ }^{2}$ Avtorji lestvice so Henri Chabrol, Amélie Rousseau in Stacey Callahan (2006). Lestvica je izvorno v angleškem jeziku in je bila za namene raziskave prevedena po metodi prevoda in vzvratnega prevoda. V slovenski jezik sta lestvico prevedli dve strokovnjakinji s področja psihologije osebnosti. Prevod je bil v angleški jezik preveden s strani kompetentne prevajalke. Postopek smo ponavljali, dokler se angleški prevod slovenske priredbe ni skladal z izvorno lestvico. Lestvica vsebuje 4 postavke, ki se nanašajo na različne vidike nestabilnosti samospoštovanja (na primer: Ob nekaterih priložnostih se počutim zelo nekoristno, ob drugih priložnostih pa zelo koristno). Udeleženci na štiristopenjski lestvici (od

$\overline{{ }^{1} \text { Porazdelitev vključenih spremenljivk se je statistično pomembno }}$ razlikovala od normalne, zato smo uporabili Spearmanov $\rho$.

${ }^{2} \mathrm{Za}$ namene izboljšane preglednosti in razumljivosti rezultatov smo $\mathrm{v}$ analizah uporabili obratne vrednosti spremenljivk nestabilnosti samospoštovanja (rezultat na lestvici ISES in lestvici RSES). Tako višja vrednost pri obeh merah pomeni stabilnejše samospoštovanje, nižja vrednost pa bolj nestabilno samospoštovanje. 
0 do 3) ocenijo, v kolikšni meri trditev drži za njih. Višji rezultat na lestvici nestabilnosti samospoštovanja pomeni bolj nestabilno samospoštovanje, medtem ko nižji rezultat predstavlja bolj stabilno samospoštovanje. Koeficient notranje skladnosti na naših podatkih znaša 0,79 . Avtorji lestvice poročajo o nekoliko višjem koeficientu notranje skladnosti $(\alpha=0,89)$. S komponentno analizo smo potrdili enodimenzionalno strukturo lestvice tudi na slovenskem vzorcu (izločena komponenta pojasni 62,74\% variance).

Vprašalnik narcisizma NPI. Avtorja vprašalnika sta Robert Raskin in Howard Terry (1988). Uporabili smo priredbo $\mathrm{v}$ slovenskem jeziku, ki je bila izvedena na Oddelku za psihologijo Filozofske fakultete v Ljubljani. Podatka o avtorju priredbe nismo uspeli pridobiti. Vprašalnik sestavlja 40 parov postavk tipa prisilne izbire (na primer: A - Nisem prepričan/-a, da bi bil/-a dober vodja, B - Vidim se kot dobrega vodjo). Vsak odgovor, ki se nanaša na narcisizem, je vrednoten $z$ eno točko. Višji rezultat na vprašalniku pomeni bolj izraženo osebnostno potezo narcisizma. Koeficient notranje skladnosti celotnega vprašalnika NPI znaša na naših podatkih 0,81 . Avtorja vprašalnika navajata nekoliko višji koeficient notranje skladnosti $(\alpha=0,83)$.

Vprašalnik psihološkega blagostanja. Avtorica vprašalnika je Carol Ryff (1989). Uporabili smo priredbo v slovenskem jeziku (Avsec in Sočan, 2009). Vprašalnik sestavlja 84 postavk, s katerimi merimo kognitivni vidik subjektivnega zadovoljstva (na primer: Ko pomislim na svoje življenje, sem zadovoljen s tem, kako so se stvari obrnile). Vprašalnik vsebuje pozitivne in negativne postavke, pri katerih mora posameznik na šeststopenjski lestvici (od 1 do 6) oceniti, v kolikšni meri te trditve zanj držijo. Višji rezultat na vprašalniku predstavlja višje psihološko blagostanje posameznika. Vprašalnik zajema tudi šest poddimenzij, ki jih v pričujoči raziskavi podrobneje nismo analizirali. $\mathrm{V}$ rezultatih smo uporabili le skupni rezultat na vprašalniku. Koeficienti notranje skladnosti posameznih poddimenzij slovenske priredbe vprašalnika znašajo med 0,80 in 0,88 . Na našem vzorcu se koeficienti notranje skladnosti posameznih dimenzij gibljejo med 0,75 in 0,89 ter 0,95 za celoten vprašalnik.

\section{Postopek}

Za zbiranje podatkov smo z uporabo spletne aplikacije Google Dokumenti (angl. Google Docs) ustvarili skupni vprašalnik, ki je vseboval vse instrumente in dodatna vprašanja o demografskih spremenljivkah udeležencev. Zbiranje podatkov je potekalo en mesec. Udeleženci so $\mathrm{V}$ raziskavi sodelovali $14 \mathrm{dni}$. Vprašalnike so reševali vse dni zaporedoma, ob približno istem času, v večernih urah dneva. Vsak od udeležencev je vsak dan prejel elektronsko pošto $\mathrm{z}$ opomnikom in podatkom o tem, katere vprašalnike naj izpolni tisti dan. Za zagotavljanje anonimnosti in možnosti longitudinalnega spremljanja rezultatov je vsak udeleženec prejel šifro ali pa si jo je izbral sam. Pred vsakim izpolnjevanjem vprašalnika je bil zahtevan vpis šifre. Na začetku izpolnjevanja (prvi dan) je vsak od udeležencev podal podatke o spolu, starosti, univerzi in fakulteti, ki jo obiskuje, ter smeri študija. Nato so izpolnili štiri vprašalnike, ki so podrobneje opisani med pripomočki. Naslednjih 13 dni so udeleženci izpolnjevali Rosenbergovo lestvico samospoštovanja. Lestvica je bila za longitudinalno rabo modificirana tako, da je bilo udeležencem naročeno, naj odgovarjajo v skladu s trenutnim počutjem in ne na splošno. Na koncu vsakokratnega izpolnjevanja je bilo dodano še vprašanje o datumu in času izpolnjevanja. V nadaljnjo analizo smo vključili le tiste udeležence, ki so vprašalnike izpolnjevali vseh 14 dni zaporedoma.

\section{Rezultati}

Najprej smo izračunali opisne statistike in korelacije med spremenljivkami. Nadalje smo preverili odnos med stabilnostjo samospoštovanja in narcisizmom. Navajamo rezultate hierarhične regresije, kjer smo ocenili prispevek tako stopnje kot stabilnosti samospoštovanja $\mathrm{k}$ rezultatom narcisizma, preverili pa smo tudi točnost samoocene stabilnosti samospoštovanja pri posameznikih z različno izraženo potezo narcisizma. V nadaljevanju smo natančneje preverili tudi odnos med stabilnostjo samospoštovanja in psihološkim blagostanjem.

Osnovne opisne statistike in korelacije med spremenljivkami so prikazane $\mathrm{v}$ tabeli 1. Porazdelitev vključenih spremenljivk se je statistično pomembno razlikovala od normalne, zato smo uporabili Spearmanov $\rho$.

Preliminarne korelacijske analize so pokazale, da narcisizem statistično pomembno pozitivno korelira $\mathrm{S}$ stopnjo samospoštovanja ter $\mathrm{s}$ samoocenjeno stabilnostjo samospoštovanja, medtem ko s stabilnostjo samospoštovanja, ocenjeno kot razpršenost stopnje samospoštovanja (glej poglavje Pripomočki) korelira statistično pomembno negativno.

Vzorci korelacij med psihološkim blagostanjem in stabilnostjo samospoštovanja so prav tako odvisni od načina merjenja stabilnosti samospoštovanja. Tako psihološko blagostanje $\mathrm{s}$ samoocenjeno stabilnostjo samospoštovanja korelira statistično pomembno pozitivno, medtem ko s stabilnostjo samospoštovanja, ocenjeno kot razpršenost stopnje samospoštovanja $\mathrm{v}$ času, ne korelira statistično pomembno. S stopnjo samospoštovanja se tako narcisizem kot psihološko blagostanje povezujeta statistično pomembno pozitivno.

\section{Stabilnost samospoštovanja in narcisizem}

Odnos med stabilnostjo samospoštovanja in narcisizmom variira glede na stopnjo samospoštovanja. Zaradi tega smo izvedli hierarhično multiplo regresijo z metodo enter, kjer smo lahko preverili odnos med stabilnostjo samospoštovanja in narcisizmom ob upoštevanju stopnje samospoštovanja. V prvi korak smo vključili spremenljivki spol in stopnja samospoštovanja, $\mathrm{v}$ drugega pa stabilnost samospoštovanja. Rezultati hierarhične regresije so povzeti v tabeli 2 . 
Tabela 1. Osnovne opisne statistike za spremenljivke, vključene v raziskavo, in Spearmanovi koeficienti korelacije med njimi

\begin{tabular}{lrrrrrr}
\hline & $M$ & $S D$ & RSES & RSES $_{\text {SD }}$ & ISES & NPI \\
\hline RSES & 22,49 & 4,65 & & & & \\
RSES $_{\text {SD }}$ & 9,76 & 2,18 & $-0,15$ & & & \\
ISES & 5,41 & 2,07 & $0,36^{* *}$ & $-0,05$ & $-0,16^{*}$ & $0,17^{*}$ \\
NPI & 14,13 & 6,26 & $0,28^{* *}$ & 0,05 & $0,23^{* *}$ & $0,20^{* *}$ \\
PWBS & 379,87 & 45,84 & $0,45^{* *}$ & 0,05
\end{tabular}

Opombe. RSES = povprečje vsakodnevnih rezultatov na lestvici samospoštovanja; $\mathrm{RSES}_{\mathrm{SD}}=$ standardna deviacija vsakodnevnih rezultatov na lestvici samospoštovanja; ISES = rezultat na lestvici nestabilnosti samospoštovanja; NPI = skupni rezultat na vprašalniku narcisizma; PWBS = skupni rezultat na vprašalniku psihološkega blagostanja.

${ }^{*} p<0,05 ;{ }^{* *} p<0,01$.

Rezultati so pokazali, da spremenljivki spol in stopnja samospoštovanja v prvem koraku pojasnita $9,0 \%$ variance skupnega rezultata na vprašalniku NPI. Glavni učinek spola v prvem koraku ni bil statistično pomemben, medtem ko je stopnja samospoštovanja pojasnila statistično pomemben delež variabilnosti skupnega rezultata na vprašalniku.

$\mathrm{V}$ drugem koraku hierarhične regresije smo k modelu dodali še stabilnost samospoštovanja. Tudi ta povezava je bila statistično pomembna in je, ob upoštevanju stopnje samospoštovanja, dodatno pojasnila statistično pomembno večji delež variance v rezultatu na vprašalniku narcisizma, $\Delta R^{2}=0,05 ; F(3,174)=9,44 ; \quad p<0,001$. Skupno model pojasni $14 \%$ variabilnosti rezultata na vprašalniku narcisizma. Po Cohenu (1988; v Elis, 2010) lahko to opredelimo kot srednje visok delež pojasnjene variabilnosti.

$\mathrm{Na}$ podlagi rezultatov lahko za posameznike z višjo stopnjo samospoštovanja pričakujemo višje vrednosti na vprašalniku narcisizma. Ob upoštevanju učinkov stopnje samospoštovanja ima stabilnost samospoštovanja negativne regresijske uteži, kar kaže na to, da lahko pri posameznikih $\mathrm{z}$ nestabilnim samospoštovanjem pričakujemo višje vrednosti na vprašalniku narcisizma.

Tabela 2. Povzetek analize hierarhične regresije za spol, stopnjo in stabilnost samospoštovanja kot prediktorje dosežkov na lestvici narcisizma

\begin{tabular}{lrrrr}
\hline Prediktor & $\Delta R^{2}$ & $B$ & $95 \% \mathrm{IZ} \mathrm{za} B$ & $\beta$ \\
\hline 1. korak & $0,09^{* * *}$ & & & \\
Spol & & $-2,05$ & {$[-4,17,0,68]$} & $-0,14$ \\
Stopnja SS & & 0,35 & {$[0,16,0,54]$} & $0,26^{* * *}$ \\
2. korak & $0,05^{* *}$ & & & \\
Spol & & $-2,15$ & {$[-4,22,-0,08]$} & $-0,15^{*}$ \\
Stopnja SŠ & & 0,31 & {$[0,12,0,50]$} & $0,23^{* *}$ \\
Stabilnost SS̆ & & $-0,62$ & {$[-1,03,-0,22]$} & $-0,22^{* *}$ \\
Skupni $R^{2}$ & $0,14^{* * *}$ & & & \\
SM 90\% IZ za $R^{2}$ & 0,06 & & & \\
\hline
\end{tabular}

Opombe. $N=178$. SM $90 \% \mathrm{IZ}=$ spodnja meja 90-odstotnega intervala zaupanja; vrednosti za spol: $0=$ moški, $1=$ ženski. ${ }^{*} p<0,05 ;{ }^{* *} p<0,01 ;{ }^{* * *} p<0,001$.
Točnost samoocene stabilnosti samospoštovanja. Kot je razvidno iz tabele 1, je korelacija med obema merama stabilnosti samospoštovanja zelo nizka in statistično nepomembna. To kaže na določena odstopanja v stabilnosti samospoštovanja, ko je ta merjena prek izračuna standardnih deviacij rezultatov večkratnih merjenj od tega, ko je merjena s samooceno. Zaradi tega smo se odločili preveriti tudi razlike $\mathrm{v}$ točnosti ocene stabilnosti samospoštovanja med posamezniki $\mathrm{z}$ bolj oziroma manj izraženim narcisizmom. Glede na mere srednjih vrednosti narcisizma (mediana) smo udeležence glede na to spremenljivko razdelili na dva dela; in sicer na posameznike $\mathrm{z}$ nizko in visoko izraženim narcisizmom. Predvidevamo, da je izračunana standardna deviacija večkratnih merjenj samospoštovanja z lestvico RSES (v nadaljevanju $\mathrm{SS}_{\mathrm{SD}}$ ) boljši indikator dejanske stabilnosti kot pa rezultat na lestvici stabilnosti samospoštovanja ISES (v nadaljevanju $\mathrm{SS}_{\mathrm{SP}}$ ). Posledično smo spremenljivko $\mathrm{SS}_{\mathrm{SD}}$ določili kot dejansko stabilnost samospoštovanja, spremenljivko $\mathrm{SS}_{\mathrm{SP}}$ pa kot samooceno stabilnosti samospoštovanja.

Zaradi primerljivosti rezultatov smo obe meri samospoštovanja $\left(\breve{S S}_{\mathrm{SD}}\right.$ in $\left.\mathrm{SS}_{\mathrm{SP}}\right)$ standardizirali in pridobili z-vrednosti teh spremenljivk. Od standardizirane spremenljivke dejanske stabilnosti samospoštovanja $\mathrm{SS}_{\mathrm{SD}}$ smo nato odšteli standardizirane vrednosti spremenljivke samoocene stabilnosti samospoštovanja $\mathrm{SS}_{\mathrm{SP}}$ in tako določili mero pod- oziroma precenjevanja stabilnosti samospoštovanja. Pozitiven rezultat tako predstavlja podcenjevanje stabilnosti samospoštovanja (posameznik ima bolj stabilno samospoštovanje, kot to sam ocenjuje); medtem ko negativen rezultat predstavlja precenjevanje stabilnosti samospoštovanja (posameznik ima manj stabilno samospoštovanje, kot to sam ocenjuje).

$\mathrm{Za}$ preverjanje razlik $\mathrm{v}$ točnosti ocene stabilnosti samospoštovanja med posamezniki znizko in posamezniki zvisokoizraženimnarcisizmom smo primerjaliaritmetični sredini spremenljivke točnosti ocene samospoštovanja med obema skupinama udeležencev. Udeležence smo glede na mediano $(M d n=14)$ razdelili v dve skupini: tiste $\mathrm{z}$ visoko izraženim narcisizmom in tiste $\mathrm{z}$ nizko izraženim narcisizmom. 
Posamezniki $\mathrm{z}$ bolj izraženim narcisizmom so $\mathrm{v}$ povprečju precenjevali stabilnost svojega samospoštovanja $(M=-0,24, S D=1,56$, min $=-5,25$, max $=2,84)$, medtem ko so posamezniki z manj izraženim narcisizmom $\mathrm{v}$ povprečjupodcenjevalistabilnostsvojegasamospoštovanja $(M=0,27, S D=1,25, \min =-3,44, \max =3,16)$. Razlika je statistično pomembna $(U=3157,00, p=0,04, r=-0,16)$, kar smo preverili z Mann-Whitney U testom.

\section{Stabilnost samospoštovanja in psihološko blagostanje}

Zanimalo nas je, ali je stabilnost samospoštovanja statistično pomemben napovednik psihološkega blagostanja, ob upoštevanju učinkov spola in stopnje samospoštovanja. Izvedli smo hierarhično regresijo $\mathrm{z}$ metodo enter. V prvem koraku smo v model vključili spol in stopnjo samospoštovanja, $\mathrm{v}$ drugem koraku pa smo vnesli stabilnost samospoštovanja. Rezultati hierarhične regresije so povzeti v tabeli 3 .

Spremenljivki spol in stopnja samospoštovanja $\mathrm{v}$ prvem koraku pojasnita $25 \%$ variabilnosti psihološkega blagostanja. K modelu največ prispeva stopnja samospoštovanja. Pomemben delež variance psihološkega blagostanja pojasni tudi spol. Ob upoštevanju spola in stopnje samospoštovanja je stabilnost samospoštovanja dodatno pojasnila statistično pomemben delež variance psihološkega blagostanja, $\Delta R^{2}=0,05 ; F(3,174)=24,56$; $p<0,001$. Celoten model pojasni skupno $30 \%$ variance psihološkega blagostanja, kar lahko po Cohenu (1988; v Elis, 2010) opredelimo kot visok delež pojasnjene variabilnosti. Glede na rezultate, lahko pričakujemo višje psihološko blagostanje pri ženskah ter pri posameznikih z višjo stopnjo in (ob upoštevanju učinkov spola in stopnje samospoštovanja) višjo stabilnostjo samospoštovanja.

Da bi preverili ali je sočasna višja izraženost tako stopnje kot stabilnosti samospoštovanja povezana $\mathrm{z}$ višjim psihološkim blagostanjem, smo udeležence razvrstili v tri kategorije: tiste, ki so na obeh merah dosegli rezultat pod mediano $(N=40)$, tiste, ki so na obeh merah dosegli

Tabela 3. Povzetek analize hierarhične regresije za spol, stopnjo in stabilnost samospoštovanja kot prediktorje dosežkov na vprašalniku psihološkega blagostanja

\begin{tabular}{lrrrr}
\hline Prediktor & $\Delta R^{2}$ & $B$ & $95 \%$ IZ za $B$ & $\beta$ \\
\hline 1. korak & $0,25^{* * *}$ & & & \\
Spol & & 29,83 & {$[15,72,43,95]$} & $0,28^{* * *}$ \\
Stopnja SS & & 4,41 & {$[3,13,5,69]$} & $0,45^{* * *}$ \\
2. korak & $0,05^{* *}$ & & & \\
Spol & & 30,58 & {$[16,88,44,28]$} & $0,28^{* * *}$ \\
Stopnja SŠ & & 4,69 & {$[3,43,5,94]$} & $0,48^{* * *}$ \\
Stabilnost SŠ & & 4,65 & {$[1,99,7,32]$} & $0,22^{* *}$ \\
Skupni $R^{2}$ & $0,30^{* * *}$ & & & \\
SM 90\% IZ za $R^{2}$ & 0,21 & & &
\end{tabular}

Opombe. $N=178$. SM $90 \% \mathrm{IZ}=$ spodnja meja 90-odstotnega intervala zaupanja; vrednosti za spol: $0=$ moški, $1=$ ženski. ${ }^{* *} p<0,01 ;{ }^{* * *} p<0,001$ rezultat nad mediano $(N=36)$, ter vse ostale $(N=102)$.

Rezultati analize variance so pokazali, da so se oblikovane skupine udeležencev med seboj statistično pomembno razlikovale v psihološkem blagostanju, $F(2$, 175) $=10,92 ; p<0,001$; parcialna $\eta^{2}=0,11$.

Najvišje vrednosti psihološkega blagostanja so dosegali posamezniki $\mathrm{z}$ visoko stopnjo in visoko stabilnostjo samospoštovanja $(M=407,80 ; S D=33,92)$, nekoliko manj posamezniki s kombinacijo nizke stopnje in visoke stabilnosti samospoštovanja oziroma obratno $(M=376,88 ; S D=44,61)$, najnižje vrednosti psihološkega blagostanja pa so dosegali tisti z nizko stopnjo in nizko stabilnostjo samospoštovanja $(M=362,35 ; S D=47,88)$. Ali so razlike med skupinami statistično pomembne smo preverili s Scheffejevim post hoc testom. Razlike med prvo (stopnja in stabilnost SŠ pod mediano) in tretjo skupino (kombinacija nizke stopnje in visoke stabilnosti samospoštovanja oziroma obratno) niso bile statistično pomembne. Razlike so se izkazale kot statistično pomembne pri primerjavi druge skupine (stopnja in stabilnost SŠ nad mediano) z ostalima skupinama (stopnja in stabilnost SŠ pod mediano ter stopnja in stabilnost S $\breve{S}$ kombinirano).

\section{Razprava}

\section{Stabilnost samospoštovanja in narcisizem}

Rezultati so pokazali, da se narcisizem pozitivno povezuje s stopnjo samospoštovanja, kar se sklada $\mathrm{s}$ preteklimi ugotovitvami (Brown in Zeigler-Hill, 2004; Campbell, 2001) in kaže na to, da lahko pri posameznikih z bolj izraženim narcisizmom pričakujemo višje samovrednotenje (Campbell in Buffardi, 1998). Glede povezave med narcisizmom in stabilnostjo samospoštovanja so rezultati nekoliko manj jasni zaradi nepovezanosti dveh uporabljenih mer stabilnosti samospoštovanja, kar problematiziramo nekoliko kasneje. Če se osredotočimo na pogosteje uporabljano mero stabilnosti samospoštovanja (variacije v večkrat merjenem samospoštovanju), se rezultati skladajo s pričakovanji in ugotovitvami nekaterih preteklih raziskav (Rhodewalt idr., 1998).

Preverili smo tudi, ali stopnja in stabilnost samospoštovanja napovedujeta narcisizem. Rezultati so pokazali, da lahko višje vrednosti na vprašalniku narcisizma pričakujemo pri posameznikih z višjo stopnjo samospoštovanja ter nestabilnim samospoštovanjem, kar se sklada s pričakovanji. Samopodoba ter samospoštovanje posameznikov z bolj izraženim narcisizmom sta pretirano odvisna od povratnih informacij drugih oseb (Rhodewalt idr., 1998), kar take posameznike vodi $\mathrm{k}$ vedenju, ki je zelo osredotočeno na iskanje zunanjih potrditev. Čeprav posamezniki $\mathrm{z}$ višje izraženim narcisizmom "uporabljajo" druge ljudi za zviševanje lastne vrednosti, pa jim ti hkrati predstavljajo vedno prisotno grožnjo za njihovo samospoštovanje (Morf in Rhodewalt, 1993), saj omogočajo socialno primerjavo, ki ni nujno vedno 
v njihov prid. Čeprav se v raziskavah največ pozornosti namenja reaktivnosti, povezani z negativnimi povratnimi informacijami, je tukaj pomembno poudariti, da so posamezniki z višje izraženim narcisizmom občutljivi tako na pozitivne kot negativne povratne informacije, kar rezultira v bolj ekstremnih emocionalnih reakcijah (Kernis in Lakey, 2010). Zaradi tega lahko predvidevamo, da so posamezniki z bolj izraženim narcisizmom izpostavljeni velikim nihanjem $\mathrm{v}$ lastnem samospoštovanju, kar potrjujejo tudi rezultati naše raziskave.

Meri stabilnosti samospoštovanja, ki smo ju v pričujoči raziskavi uporabili, nista statistično pomembno korelirali, kar nakazuje na pomembne razlike $\mathrm{v}$ oceni stabilnosti samospoštovanja, ko primerjamo bolj "neposredno" samooceno stabilnosti samospoštovanja ter oceno stabilnosti samospoštovanja na podlagi nihanj v vsakodnevnem samospoštovanju.

Glede na izsledke raziskav, ki so preučevale točnost ocen posameznikov z bolj izraženo osebnostno potezo narcisizma na drugih področjih, kot so na primer inteligentnost, moč in fizična privlačnost (Buffardi in Campbell, 2008), smo predvidevali, dabodo ti posamezniki precenjevali stabilnost lastnega samospoštovanja. Rezultati so predvidevanja potrdili. Ugotovili smo, da posamezniki $\mathrm{z}$ bolj izraženo osebnostno potezo narcisizma bistveno bolj precenjujejo stabilnost svojega samospoštovanja $\mathrm{v}$ primerjavi $\mathrm{s}$ posamezniki $\mathrm{z}$ manj izraženo osebnostno potezo narcisizma. Precenjevanje stabilnosti samospoštovanja tistih $\mathrm{z}$ bolj izraženim narcisizmom se sklada $\mathrm{z}$ ugotovitvami raziskav, da visoko narcisistični posamezniki precenjujejo svoje pozitivne lastnosti in imajo precej netočne samozaznave (Buffardi in Campbell, 2008). Dodatna zanimiva ugotovitev je, da posamezniki z manj izraženim narcisizmom v povprečju podcenjujejo stabilnost svojega samospoštovanja. Čeprav posebnega odnosa $\mathrm{z}$ mero točnosti ocene stabilnosti samospoštovanja pri tej skupini nismo predvideli, je rezultat vendarle presenetljiv. Ker raziskav na tem področju primanjkuje, bi bilo ta odnos potrebno še podrobneje preučiti.

\section{Stabilnost samospoštovanja in psihološko blagostanje}

Predstavljeni rezultati kažejo, da sta tako stopnja kot stabilnost samospoštovanja pomembna dejavnika psihološkega blagostanja. Potrdili smo ugotovitve preteklih raziskav (npr. Ryff, 1989), da je stopnja samospoštovanja statistično pomemben napovednik psihološkega blagostanja (pričakujemo lahko višje vrednosti psihološkega blagostanja pri posameznikih z višjo stopnjo samospoštovanja). Ugotovitev, da lahko preko stopnje samospoštovanja napovedujemo psihološko blagostanje kaže na pomembno vlogo samospoštovanja pri pozitivnem kognitivnem in emocionalnem vrednotenju lastnega življenja (Ryff, 1989). Dodatno smo uspeli pokazati, da stabilnost samospoštovanja, ob upoštevanju stopnje samospoštovanja, pojasni dodaten, statistično pomembno velik delež variabilnosti v psihološkem blagostanju. To kaže na pomembno vlogo stabilnosti samospoštovanja $\mathrm{v}$ psihološkem blagostanju, ter se sklada z ugotovitvami preteklih raziskav, ki nestabilno samospoštovanje konsistentno povezujejo z negativnimi psihološkimi izidi, npr. depresivnim razpoloženjem, nejasno samopodobo, nižjo intrinzično motivacijo itd. (npr. Kernis idr., 2000; Roberts in Monroe, 1992; Waschull in Kernis, 1996). Pokazali smo tudi, da posamezniki z visoko stopnjo ter stabilnostjo samospoštovanja dosegajo višje vrednosti psihološkega blagostanja, kot posamezniki z visoko stopnjo samospoštovanja ter nizko stabilnostjo samospoštovanja ali obratno. Ugotovitev dodatno potrjuje ključno vlogo stabilnosti samospoštovanja v psihološkem funckioniranju. Ena izmed možnih interpretacij teh rezultatov je, da enako kot višja stopnja stabilnega samospoštovanja predstavlja osnovo za učinkovito psihološko funkcioniranje, prisotnost nestabilnih občutkov samospoštovanja učinkovito psihološko funkcioniranje otežuje. To se lahko dogaja tudi indirektno, preko pogostejšega obrambnega vedenja, jeze ali emocionalne reaktivnosti (Kernis in Lakey, 2010). Nestabilno samospoštovanje lahko preko pogostega samopoveličevanja in uporabe obrambnih strategij tako prepreči bolj učinkovite odzive (Paradise in Kernis, 2002).

Vse naštete ugotovitve kažejo na pomembnost upoštevanja tako stopnje kot stabilnosti samospoštovanja, pri napovedovanju izidov ter psihološkega funkcioniranja.

\section{Zaključki}

Rezultati pričujoče raziskave osvetljujejo pomembno vlogo stabilnosti samospoštovanja za psihološko funkcioniranje posameznikov ter kažejo na veliko napovedno vrednost stabilnosti samospoštovanja pri teh izidih.

Pričujoča raziskava ima določene omejitve, ki so lahko pomembno prispevale $\mathrm{k}$ rezultatom. Težava se pojavlja pri merjenju stabilnosti samospoštovanja. Čeprav je izračun standardnih deviacij že utečena praksa v raziskavah stabilnosti samospoštovanja, se pojavlja vprašanje, ali je lestvica samospoštovanja RSES dovolj občutljiva za odkrivanje subtilnih razlik v stabilnosti samospoštovanja. Prav tako pa se pojavljajo vprašanja glede resnosti pristopa udeležencev k reševanju. Glede na to, da so udeleženci 14 dni zaporedoma reševali vprašalnik samospoštovanja RSES, lahko hitro pride do rutinskega, avtomatičnega odgovarjanja na vprašalniku. Ker pri spletnem načinu administracije vprašalnika nimamo nadzora nad vedenjem udeležencev med reševanjem, je pomislek glede veljavnosti njihovega samoporočanja potrebno upoštevati pri interpretaciji rezultatov. Kot pomanjkljivost lahko izpostavimo tudi način merjenja stopnje samospoštovanja. Prvo merjenje samospoštovanja (reševanje lestvice samospoštovanja prvi dan) in povprečje rezultatov v štirinajstih dneh reševanja sta izjemno visoko 
korelirala $(\rho=0,92, p<0,01)$, kar nakazuje na to, da ti dve spremenljivki prikazujeta isti konstrukt. Vseeno pa moramo upoštevati dejstvo, da je bila uporaba lestvice samospoštovanja RSES zaradi longitudinalne rabe prilagojena tako, da je od udeleženca zahtevala reševanje glede na trenutno počutje in ne na splošno, kot je to $\mathrm{V}$ izvirni rabi lestvice. Najbolj optimalno bi bilo, če bi lestvico samospoštovanja udeleženci rešili nekaj časa pred vsakodnevnim reševanjem (na primer en mesec prej), navodilo pa bi bilo enako, kot se uporablja pri enkratnem merjenju (reševanje lestvice na splošno in ne glede na trenutno počutje). To bi bilo vsekakor dobro upoštevati pri morebitnih nadaljnjih raziskavah tega področja. Da bi raziskovalne rezultate lahko posploševali na celotno slovensko študentsko populacijo, bi bilo potrebno pridobiti vzorec, proporcionalen s slovenskim prebivalstvom glede na spol, starost, smer študija in še glede na kakšen drug demografski podatek. Dodaten pomislek pri udeležencih povzroča možnost, da se udeleženci sistematično razlikujejo od tistih, ki se pri raziskavi niso odločili sodelovati, kar lahko vpliva na dobljene rezultate.

V nadaljnjih raziskavah bi bilo dobro bolj poglobljeno preučiti povezave stabilnosti samospoštovanja $\mathrm{z}$ narcisizmom in s psihološkim blagostanjem. Potrebno bi bilo še bolj raziskati odnos med stabilnostjo samospoštovanja $\mathrm{z}$ drugimi konstrukti pri posameznikih z nizkim samospoštovanjem, saj so avtorji na tem področju do sedaj raziskovali predvsem posameznike z visokim samospoštovanjem. V raziskovanje povezanosti stabilnosti samospoštovanja in narcisizma bi bilo dobro vključiti tudi različne podtipe narcisizma (odkriti in prikriti narcisizem), katerih uporaba je $\mathrm{v}$ raziskavah narcisizma vse bolj aktualna (glej npr. Rose, 2002).

Zaradi korelacijske narave naših podatkov je potrebna previdnost pri nakazovanju na morebitne kavzalne zveze med pojavi. Za takšne sklepe bi bile potrebne longitudinalne raziskave. Vseeno pa je pomemben prispevek te raziskave ta, da dodatno kaže na razlike znotraj skupine posameznikov $\mathrm{z}$ isto stopnjo samospoštovanja (bodisi nizko, bodisi visoko), ki se pogosto, vendar $\mathrm{v}$ določenih primerih neupravičeno, obravnava kot homogena skupina.

\section{Literatura}

Avsec, A. (2007). Lestvica samospoštovanja RSES. V A. Avsec (ur.), Psihodiagnostika osebnosti (str. 103110). Ljubljana, SLO: Filozofska fakulteta Univerze v Ljubljani, Oddelek za psihologijo.

Avsec, A. in Sočan, G. (2009). Validacija slovenske oblike Vprašalnika psihološkega blagostanja RPWB. Psihološka obzorja, 18(4), 19-36.

Baumeister, R. F., Campbell, J. D., Krueger, J. I. in Vohs, K. D. (2003). Does high self-esteem cause better performance, interpersonal success, hapiness, or healthier lifestyles? Psychological Science in the Public Interest, 4(1), 1-44.

Baumeister, R. F., Heatheron, T. F. in Tice, D. M. (1993). When ego treats lead to self-regulation failure: Negative consequences of high self-esteem. Journal of Personality and Social Psychology, 64(1), 141-156.
Bosson, J. K., Lakey, C. E., Campbell, W. K., Zeigler-Hill, V., Jordan, C. H. in Kernis, M. H. (2008). Untangling the links between narcissism and self-esteem: A theoretical and empirical review. Social and Personality Psychology Compass, 2/3, 1415-1439.

Brown, R. P. in Zeigler-Hill, V. (2004). Narcissism and the nonequivalence of self-esteem measures: A matter of dominance? Journal of Research in Personality, 38(6), 585-592.

Buffardi, L. E. in Campbell, W. K. (2008). Narcissism and social networking web sites. Personality and Social Psychology Bulletin, 34, 1303-1314.

Campbell, W. K. (1999). Narcissism and romantic attraction. Journal of Personality and Social Psychology, 77(6), 1254-1270.

Campbell, W. K. (2001). Is narcissism really so bad? Psychological Inquiry, 12, 214-216.

Campbell, W. K., Brunell, J. K. in Finkel, E. J. (2006). Narcissism, interpersonal self-regulation, and romantic relationships: An agency model approach. In E. J. Finkel in K. D. Vohs (ur.), Self and Relationships: Connecting intrapersonal and interpersonal processes (str. 57-83). New York: Guilford.

Campbell, W. K. in Buffardi, L. E. (1998). The lure of the noisy ego: Narcissism as a social trap. V H. A. Wayment in J. J. Bauer (ur.), Transcending selfinterest: Psychological explorations of the quiet ego (str. 23-32). Washington, DC, ZDA: American Psychological Association.

Chabrol, H., Rousseau, A. in Callahan, S. (2006). Preliminary results of a scale assessing instability of self-esteem. Canadian Journal of Behavioural Science, 38(2), 136-141.

Elis, P. D. (2010). The essential guide to effect sizes: Statisticalpower, meta-analysis, andtheinterpretation of research results. New York, NY, ZDA: Cambridge University Press.

Greenier, K.D., Kernis, M.H., McNamara, C. W., Waschull, S. B., Berry, A. J., Herlocker, C. E. in Abend, T. A. (1999). Individual differences in reactivity to daily events: Examining the roles of stability and level of self-esteem. Journal of Personality, 67(1), 185-208.

Kernis, M. H. (2005). Measuring self-esteem in context: The importance of stability of self-esteem in psychological functioning. Journal of Personality, 73, 1569-1605.

Kernis, M. H., Cornell, D. P., Sun, C-R., Berry, A. in Harlow, T. (1993). There's more to self-esteem than whether it is high or low: The importance of stability of self-esteem. Journal of Personality and Social Psychology, 65(6), 1190-1204.

Kernis, M. H., Grannemann, B. D. in Mathis, L. C. (1991). Stability of self-esteem as a moderator of the relation between level of self-esteem and depression. Journal of Personality and Social Psychology, 61(1), 80-84.

Kernis, M. H. in Lakey, C. E. (2010). Fragile versus secure high self-esteem: Implications for defensiveness and insecurity. V R. M. Arkin, K. C. Oleson in P. J. Carroll (ur.), Handbook of the uncertain self (str. 360-378). New York, NY, ZDA: Psychology Press. 
Kernis, M. H., Paradise, A. W., Whitaker, D. J., Wheatman, S. R. in Goldman, B. N. (2000). Master of one's psychological domain? Not likely if one's self-esteem is unstable. Personality and Social Psychology Bulletin, 26, 1297-1305.

Kobal Grum, D. in Avsec, A. (2007). Samospoštovanje [Self-esteem]. V A. Avsec (ur.), Psihodiagnostika osebnosti [Psychodiagnostics of personality] (str. 93102). Ljubljana, SLO: Filozofska fakulteta Univerze v Ljubljani, Oddelek za psihologijo.

Morf, C. C. in Rhodewalt, F. (1993). Narcissism and self-evaluation maintenance: Explorations in object relations. Personality and Social Psychology Bulletin, 19(6), 668-676.

Paradise, A. W. in Kernis, M. H. (2002). Self-esteem and psychological well-being: Implications of fragile selfesteem. Journal of Social and Clinical Psychology, 21(4), 345-361.

Raskin, R. in Terry, H. (1988). A principal-components analysis of the narcissistic personality inventory and further evidence of its construct validity. Journal of Personality and Social Psychology, 54(5), 890-902.

Rhodewalt, F., Madrian, J. C. in Cheney, S. (1998). Narcissism, self-knowledge organization, and emotional reactivity: The effect of daily experiences on self-esteem and affect. Personality and Social Psychology Bulletin, 24(1), 75-87.

Roberts, J. E. in Monroe, S. M. (1992). Vulnerable selfesteem and depressive symptoms: Prospective findings comparing three alternative conceptualizations. Journal of Personality and Social Psychology, 62(5), 804-812.

Rose, P. (2002). The happy and unhappy faces of narcissism. Personality and Individual Differences, 33(3), 379-391.

Ryff, C. D. (1989). Happiness is everything, or is it? Explorations on the meaning of psychological wellbeing. Journal of Personality and Social Psychology, 57(6), 1069-1081.

Skaalvik, E. M. in Hagtvet, K. A. (1990). Academic achievement and self-concept: An analysis of causal predominance in a developmental perspective. Journal of Personality \& Social Psychology. 58(2), 292-307.

Waschul, S. B. in Kernis, M. H. (1996). Level and stability of self-esteem as predictors of children's intrinsic motivation and reasons for anger. Personality and Social Psychology Bulletin, 22(1), 4-13.

Webster, G. D., Kirkpatrick, L. A., Nezlek, J. K., Smith, C. V. in Paddock, E. L. (2007). Different slopes for different folks: Self-esteem instability and gender as moderators of the relationship between self-esteem and attitudinal aggression. Self and Identity, 6(1), 74-94.

Zeigler-Hill, V. (2006). Discrepancies between implicit and explicit self-esteem: Implications for narcissism and self-esteem instability. Journal of Personality, 74(1), 119-144. 